\title{
VOIDING DYSFUNCTIONS AND PREVENTION AFTER PROSTATE BIOPSY: PROSPECTIVE OBSERVATIONAL STUDY
}

\author{
Aykut BAŞER ${ }^{1 *}$, Mehmet Murat BAYKAM${ }^{1}$, Mustafa Serdar ÇAĞLAYAN ${ }^{1}$, Cemil AYDIN ${ }^{1}$, Muhammet \\ YAYTOKGIL ${ }^{1}$, Musa EKICI ${ }^{1}$
}

${ }^{1}$ Hitit University, Medical Faculty, Department of Urology, 19040, Corum, Turkey

\begin{abstract}
The possible side effects of transrectal ultrasonography-guided prostate biopsy (TRUS-Bx), which is one of the most common procedure of urology practice, are common but tend to limit themselves. TRUS-Bx may be associated with Lower Urinary System Symptoms (LUTS). We aimed to investigate the effects of TRUS-Bx on LUTS and the factors that decrease or increase these effects and to provide information about the exposure periods of these factors. This study is a prospective observational study involving patients undergoing prostate biopsy between August 1st, 2019 to 2020. Detailed history was obtained and physical examinations were evaluated from all patients. Patients' age, PSA levels, prostate volumes, Body-Mass-Index measurements and use of alpha blocker were recorded. The effects of recorded information of patients with prostate biopsy on LUTS and uroflowmetry parameters were investigated. A total of 143 patients were included in the study after determining the exclusion criteria. A significant correlation was found only between Qmax changes after TRUS-Bx and the use of alpha blockers. All patients, have decreased Qmax flow rate observed at postprocedure 1th day compared to baseline values. During the controls performed in the 4th week, while the decrease in patients using alpha blockers reached a significantly higher value than its baseline value, it could not return to its baseline value in patients who do not use alpha blockers. Prostate biopsy is expected to cause a temporary LUTS. The effects on this LUTS can be corrected with the use of alpha blockers.
\end{abstract}

Keywords: Prostate biopsy, Voiding dysfunction, LUTS, Alpha blockers, International prostate symptom score

\begin{tabular}{|c|c|}
\hline \multicolumn{2}{|c|}{$\begin{array}{l}\text { *Corresponding author: Hitit University, Medical Faculty, Department of Urology } \\
\text { E mail: aqut85@windowslive.com (A. BAȘER) }\end{array}$} \\
\hline Aykut BAȘER & https://orcid.org/0000-0003-0457-512X \\
\hline Mehmet Murat BAYKAM & https://orcid.org/0000-0001-9006-4275 \\
\hline Mustafa Serdar ÇAĞLAYAN & https://orcid.org/0000-0002-5086-8671 \\
\hline Cemil AYDIN & https://orcid.org/0000-0002-7271-5748 \\
\hline Muhammet YAYTOKGIL & https://orcid.org/0000-0002-4956-2659 \\
\hline Musa EKICI & https://orcid.org/0000-0002-9155-4126 \\
\hline
\end{tabular}

Received: January 04, 2021 Accepted: January 10, 2021 Published: May 01, 2021

Cite as: Başer A, Baykam MM, Çağlayan MS, Aydın C, Yaytokgil M, Ekici M. 2021. Voiding dysfunctions and prevention after prostate biopsy: Prospective observational study. BSJ Health Sci, 4(2): 114-119.

\section{Introduction}

After the use of prostate-specific antigen (PSA) as a serum marker in the diagnosis of prostate cancer ( $\mathrm{PCa}$ ), Transrectal ultrasonography-guided prostate biopsy (TRUS-Bx) was applied by Hodge et al. for the first time in 1989, and it is considered as the standard method in the diagnosis of prostate cancer (Stamey et al., 1987; Hodge et al., 1989). It is estimated that over 1 million procedures are performed each year in the United States and in Europe with TRUS-Bx, which is a gold standard technique that confirms the presence of cancer in men with suspected prostate malignancy (Loeb et al., 2011; Loeb et al., 2013). The possible side effects of TRUS-Bx, which is one of the most common procedures of urology practice, are common but tend to limit themselves. The most common complications of prostate biopsy, which is performed as a safe procedure, are indicated to be hematospermia (37.4\%), hematuria $(14.5 \%)$, rectal bleeding $<2$ days $(2.2 \%)$, prostatitis $(1.0 \%),>38.5^{\circ}$ fever $(0.8 \%)$, epididymitis $(0.7 \%)$ and urinary retention
(0.2\%) (Mottet et al., 2020).

In addition to these complications, it was demonstrated in some studies that TRUS-Bx may also be associated with other urological conditions, including erectile dysfunction and/or Lower Urinary System Symptoms (LUTS) (Glaser et al., 2012). LUTS, which is reported at the rates of $6 \%$ and $25 \%$ after TRUS-Bx in the literature, is an exacerbation of short-term urinary symptoms (Glaser et al., 2012; Loeb et al., 2013; Namekawa et al., 2015). In the literature, there are studies indicating the use of alpha blockers is useful to decrease the LUTS effects of TRUS-Bx (Bozlu et al., 2003; Chung et al., 2015; Sefik et al., 2020). In our prospective observational study, we investigated the effects of TRUS-Bx on LUTS and the factors that decrease or increase these effects. We aimed to provide information about the exposure durations of these factors as a contribution to the literature. 


\section{Material and Methods}

\subsection{Study Design and Inclusion/Exclusion Criteria}

Our research is a prospective observational study and conducted in accordance with STROBE guidelines for reporting observational studies (www.strobestatement.org). Informed consent (written) was obtained from all participants. After obtaining the institutional ethics committee approval, biopsy was performed in 189 patients who underwent TRUS-Bx for the first time between August 1 1 2019 and August 1st, 2020. Prostate biopsy indication in our study; the patients had abnormal rectal examination and / or serum PSA levels above $2.5 \mathrm{ng} / \mathrm{ml}$. History of surgical treatment for prostate, severe diabetes mellitus (patients who cannot regulate blood sugar), severe coagulation disorders (thrombocytopenia, hemophilia etc.), rectal disease such as anal fissure, anal fistula or hemorrhoid, patients with concomitant malignancies, neurological diseases, the presence of catheter and the presence of urinary infection were determined as the exclusion criteria. 143 patients were included in the study after determining the exclusion criteria.

\subsection{Data Collection and Outcome Measures}

Detailed history was obtained from all patients, and physical examinations and rectal examinations were evaluated. Patients' age, Prostate-Specific Antigen (PSA) levels, prostate volumes (width $\mathrm{x}$ length $\mathrm{x}$ depth $\mathrm{x}$ 0.52), Body Mass Index (BMI) measurements and use of alpha blocker (Patients were divided into 2 classes in terms of alpha blocker use. Patients using alpha blockers; the patients who started to use alpha blocker at least 1 month before the biopsy and who had regular use after the biopsy. Patients not using alpha blockers; the patients who use irregular alpha blockers or never use alpha blockers) and pathology results were recorded.

Uroflowmetry was performed in all patients before the TRUS-Bx, on the 1st day after biopsy and on the 4th week after biopsy, and the maximum flow rate (Qmax) rates and postvoid residual urine volume (PVR) were measured by ultrasound. The International Prostate Symptom Score (I-PSS) form was filled out before biopsy and at the 4th week after biopsy, and the scores were calculated. A questionnaire scored in the range of 0 (painless) - 10 (maximum painful) was administered to patients to evaluate their Visual Analog Scale (VAS) on the 1st day after biopsy, and the VAS score was recorded. The relationship between the changes in the Qmax values of the patients due to biopsy and age, BMI, PSA, VAS, prostate volume and the use of alpha blocker was examined by correlation analysis.

\subsection{Biopsy Procedure}

Biopsy was performed in patients with negative urine culture. Before TRUS-Bx, all patients were injected with $10 \mathrm{ml}$ of $2 \%$ prilocaine hydrochloride into the angle between the prostate gland and seminal vesicles $(5 \mathrm{~mL}$ each) using an 18-gauge needle. Prostate volumes measured by Transrectal ultrasonography (TRUS) (GE Health_Lociq 200 Pro) were recorded. As a standard practice, enema was applied to all patients in the morning on the day of biopsy and local disinfection was performed using betadine before the biopsy. 12 core systematic biopsy (12 core systematic biopsy; A total of 12 core biopsies were taken from lateral and far-lateral from the apex, middle and basis of the right and left sides of the prostate.) samples were taken from all patients using a $30 \mathrm{~cm} 18$ Gauge fully automatic biopsy needle. $500 \mathrm{mg}$ ciprofloxacin before and after the procedure only 1 day and Non-steroidal anti-inflammatory drugs (NSAID) containing dexketoprofen for 3 days after the procedure were administered to the patients who underwent biopsy.

\subsection{Statistical Analysis}

Statistical analyses were performed using the SPSS software version 22. Qmax changing and other variables were investigated using visual (histograms, probability plots) and analytical methods (KolmogorovSimirnov/Shapiro-Wilk's test) to determine whether or not they are normally distributed. Descriptive analyses were presented using means and standard deviations for normally distributed. As both parameters were normally distributed, the corelations coefficients and their significance were calculated using the Pearson test. The effect of alpha blockers using status on the change in Qmax, PVR and I-PSS by time were investigated using repeated measures analysis of variance. GreenhouseGeisser correction was used when the sphericity assumption was violated. An overall 5\% type-I error level used to infer statistical significance. And the MannWhitney $\mathrm{U}$ test to compare the values between the two groups. A P value less than 0.05 was considered statistically significant.

\subsection{Ethical Consideration}

This study was approved by the Local Ethics Committee with decision number 2019-24.

\section{Results}

\subsection{Demographic and Descriptive Data}

A total of 143 patients were included in the study after determining the exclusion criteria. The main characteristics of the patients are presented in Table 1. The correlation analysis performed between the changes in the Qmax values (named as Qmax change $1=$ Day 1 after biopsy procedure Qmax - baseline Qmax, Qmax change $2=4$ th week after biopsy procedure Qmax baseline Qmax) of the patients due to biopsy and age, BMI, PSA, VAS, prostate volume and the use of alpha blocker is presented in Table 2. A significant correlation was found only between Qmax changes and the use of alpha blockers. (Qmax change 1 and Qmax change $2 \mathrm{P}<$ 0.001 , rho -0.320 and $\mathrm{P}=0.005$, rho -0.252 , respectively). The patients were divided into two groups according to the use of alpha blockers, and their baseline characteristics and symptoms and uroflowmetry parameters were evaluated. While 51 individuals without the use of alpha blocker were grouped as group 1, 92 individuals with the use of alpha blocker were grouped 
as group 2. Age, BMI, VAS, PSA, Prostate volume, Preprocedure and Postprocedure $4^{\text {th }}$ week I-PSS, Preprocedure-Postprocedure 1st day and Postprocedure $4^{\text {th }}$ week Qmax and PVR values between both groups are presented in Table 3. Prostate volume was found to be higher in the group with the use of alpha blockers. However, no statistically significant effect was found on Qmax changes in the correlation analysis performed (Table 2).

\subsection{Symptom Score}

The changes in I-PSS scores in repeated measures in alpha blocker using group were found to be statistically significant $(\mathrm{P}=0.001)$ (Figure 1$)$. The use of alpha blockers had a significant effect on this improvement $4^{\text {th }}$ week (Table 4).
Table 1. Baseline characteristics all patients

\begin{tabular}{|c|c|c|}
\hline \multicolumn{2}{|l|}{ 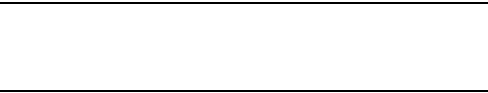 } & $\begin{array}{c}\text { Mean } \pm \text { SD } \\
(n=143)\end{array}$ \\
\hline \multicolumn{2}{|l|}{ Age (years) } & $64.69 \pm 6.70$ \\
\hline \multicolumn{2}{|l|}{ BMI $\left(\mathrm{kg} / \mathrm{m}^{2}\right)$} & $27.35 \pm 3.69$ \\
\hline \multicolumn{2}{|l|}{ PSA (ng/mL) } & $10.03 \pm 8.98$ \\
\hline \multicolumn{2}{|c|}{ Prostate Volume (ml) } & $50.10 \pm 16.28$ \\
\hline \multicolumn{2}{|l|}{ VAS } & $2.56 \pm 1.79$ \\
\hline \multicolumn{2}{|c|}{ I-PSS Preprocedure (Basaline) } & $13.83 \pm 8.17$ \\
\hline \multicolumn{2}{|c|}{$\begin{array}{l}\text { Qmax Preprocedure (Basaline) } \\
(\mathrm{mL} / \mathrm{sn})\end{array}$} & $12.86 \pm 5.58$ \\
\hline \multicolumn{2}{|c|}{ PVR Preprocedure (Basaline) (mL) } & $53.93 \pm 52.45$ \\
\hline \multirow{2}{*}{$\begin{array}{l}\text { Abnormal } \\
\text { Rectal } \\
\text { Examination }\end{array}$} & Yes (\%) & $32(22.4)$ \\
\hline & No $(\%)$ & $111(77.6)$ \\
\hline Using Alpha & Yes (\%) & $92(64.3)$ \\
\hline Blocker & No $(\%)$ & $51(35.7)$ \\
\hline Pathology & Benign (\%) & $91(63.6)$ \\
\hline Results & Malign (\%) & $52(36.4)$ \\
\hline
\end{tabular}

Table 2. The correlation analysis performed between the changes in the Qmax values of the patients due to biopsy and age, BMI, PSA, VAS, prostate volume and the use of alpha blocker.

\begin{tabular}{|c|c|c|c|c|c|c|c|}
\hline & & Age & BMI & PSA & $\begin{array}{l}\text { Prostate } \\
\text { Volume }\end{array}$ & VAS & $\begin{array}{l}\text { Using } \\
\text { Alpha } \\
\text { Blocker }\end{array}$ \\
\hline \multirow{2}{*}{$\begin{array}{l}\text { Qmax Change } 1 \\
\text { Change form basal to } \\
\text { postprocedure } 1 \text { th day }\end{array}$} & Correlation & 0.136 & 0.004 & 0.029 & -0.150 & $\begin{array}{c}- \\
0.071\end{array}$ & $-0.320^{* *}$ \\
\hline & $P$ value & 0.134 & 0.967 & 0.746 & 0.099 & 0.432 & $0.000^{*}$ \\
\hline \multirow{2}{*}{$\begin{array}{l}\text { Qmax Change } 2 \\
\text { Change form basal to } \\
\text { postprocedure 4th week }\end{array}$} & Correlation & 0.028 & 0.048 & -0.035 & -0.033 & $\begin{array}{c}- \\
0.056\end{array}$ & $-0.252^{* *}$ \\
\hline & P value & 0.758 & 0.600 & 0.705 & 0.718 & 0.542 & $0.005^{*}$ \\
\hline
\end{tabular}

BMI= body mass index, $\mathrm{PSA}=$ prostate specific antigen, $\mathrm{VAS}=$ visual analog scale.

Table 3. Baseline characteristics of groups according to the use of alpha blockers

\begin{tabular}{|c|c|c|c|c|}
\hline & & $\begin{array}{c}\text { Grup } 1 \\
\text { (using alpha blocker - ) } \\
(\mathrm{n}=51) \\
\text { Mean } \pm \text { SD }\end{array}$ & $\begin{array}{c}\text { Grup } 2 \\
\text { (using alpha blocker }+ \text { ) } \\
(\mathrm{n}=92) \\
\text { Mean } \pm \text { SD }\end{array}$ & $P$ \\
\hline \multicolumn{2}{|l|}{ Age (years) } & $65.39 \pm 7.51$ & $64.30 \pm 6.22$ & 0.354 \\
\hline \multicolumn{2}{|l|}{ BMI $\left(\mathrm{kg} / \mathrm{m}^{2}\right)$} & $26.77 \pm 3.25$ & $27.66 \pm 3.90$ & 0.194 \\
\hline \multicolumn{2}{|l|}{ PSA (ng/mL) } & $10.99 \pm 10.18$ & $9.50 \pm 8.26$ & 0.345 \\
\hline \multicolumn{2}{|c|}{ Prostate Volume (ml) } & $44.59 \pm 12.71$ & $53.15 \pm 17.28$ & 0.002 \\
\hline \multicolumn{2}{|l|}{ VAS } & $2.51 \pm 1.69$ & $2.58 \pm 1.97$ & 0.887 \\
\hline \multirow{3}{*}{ I-PSS } & Preprocedure (Basaline) & $12.64 \pm 9.56$ & $14.48 \pm 7.26$ & 0.198 \\
\hline & Postprocedure 4 Week & $12.09 \pm 8.34$ & $12.63 \pm 7.41$ & 0.694 \\
\hline & Preprocedure (Basaline) & $15.39 \pm 5.78$ & $11.17 \pm 4.77$ & $<0.001$ \\
\hline \multirow[t]{3}{*}{$\mathrm{Qmax}(\mathrm{mL} / \mathrm{sn})$} & Postprocedure Day-1 & $10.86 \pm 4.38$ & $9.71 \pm 3.95$ & 0.126 \\
\hline & Postprocedure 4 Week & $14.49 \pm 4.85$ & $12.62 \pm 4.13$ & 0.022 \\
\hline & Preprocedure (Basaline) & $45.43 \pm 35.37$ & $61.16 \pm 62.87$ & 0.116 \\
\hline \multirow[t]{2}{*}{ PVR (mL) } & Postprocedure Day-1 & $90.90 \pm 85.08$ & $75.66 \pm 60.36$ & 0.683 \\
\hline & Postprocedure 4 Week & $40.86 \pm 34.94$ & $42.38 \pm 53.52$ & 0.862 \\
\hline \multirow{2}{*}{ Pathology Results } & Benign (\%) & $38(74.4)$ & $69(75)$ & \multirow{2}{*}{0.948} \\
\hline & Malign (\%) & $13(25.5)$ & $23(25)$ & \\
\hline
\end{tabular}

BMI= body mass index, $\mathrm{Qmax}=$ maximal flow rate, $\mathrm{PVR}=$ postvoid residual, I-PSS= international prostate symptom score, VAS= visual analog scale. 
Black Sea Journal of Health Science

Table 4. Comparison of Preprocedure and Postprocedure I-PSS and Uroflowmetry parametters between the groups

\begin{tabular}{|c|c|c|c|c|c|c|}
\hline & \multicolumn{3}{|c|}{$\begin{array}{c}\text { Grup } 1(n=51) \\
\text { Mean } \pm \text { SD }\end{array}$} & \multicolumn{3}{|c|}{$\begin{array}{c}\text { Grup } 2(n=92) \\
\text { Mean } \pm S D\end{array}$} \\
\hline & \multirow{2}{*}{$\begin{array}{l}\text { Preprocedure } \\
\text { (Basaline) }\end{array}$} & \multicolumn{2}{|c|}{ Postprocedure } & \multirow{2}{*}{$\begin{array}{l}\text { Preprocedure } \\
\text { (Basaline) }\end{array}$} & \multicolumn{2}{|c|}{ Postprocedure } \\
\hline & & Day 1 & 4 week & & Day 1 & 4 week \\
\hline $\begin{array}{l}\text { Qmax } \\
\text { (mL/sn) }\end{array}$ & $15.39 \pm 5.78$ & $\begin{array}{c}10.86 \pm 4.38 \\
(\mathrm{P}<0.001)^{*}\end{array}$ & $\begin{array}{c}14.49 \pm 4.85 \\
(\mathrm{P}=0.239)^{*}\end{array}$ & $11.17 \pm 4.77$ & $\begin{array}{c}9.71 \pm 3.95 \\
(P=0.003)^{*}\end{array}$ & $\begin{array}{c}12.62 \pm 4.13 \\
(\mathrm{P}=0.001)^{*}\end{array}$ \\
\hline $\begin{array}{l}\text { PVR } \\
(\mathrm{mL})\end{array}$ & $45.43 \pm 35.37$ & $\begin{array}{l}90.90 \pm 85.08 \\
(P=0.002)^{*}\end{array}$ & $\begin{array}{l}40.86 \pm 34.94 \\
(P=0.216)^{*}\end{array}$ & $61.16 \pm 62.87$ & $\begin{array}{l}75.66 \pm 60.36 \\
(P=0.018)^{*}\end{array}$ & $\begin{array}{l}42.38 \pm 53.52 \\
(P=0.061)^{*}\end{array}$ \\
\hline I-PSS & $12.64 \pm 9.56$ & - & $\begin{array}{c}12.09 \pm 8.34 \\
(\mathrm{P}=0.118)^{*}\end{array}$ & $14.48 \pm 7.26$ & - & $\begin{array}{c}12.63 \pm 7.41 \\
(\mathrm{P}<0.001)^{*}\end{array}$ \\
\hline
\end{tabular}

Qmax= maximum flow rate, $\mathrm{PVR}=$ postvoid residual, I-PSS= international prostate symptom score.

*=compared to Preprocedure (baseline).
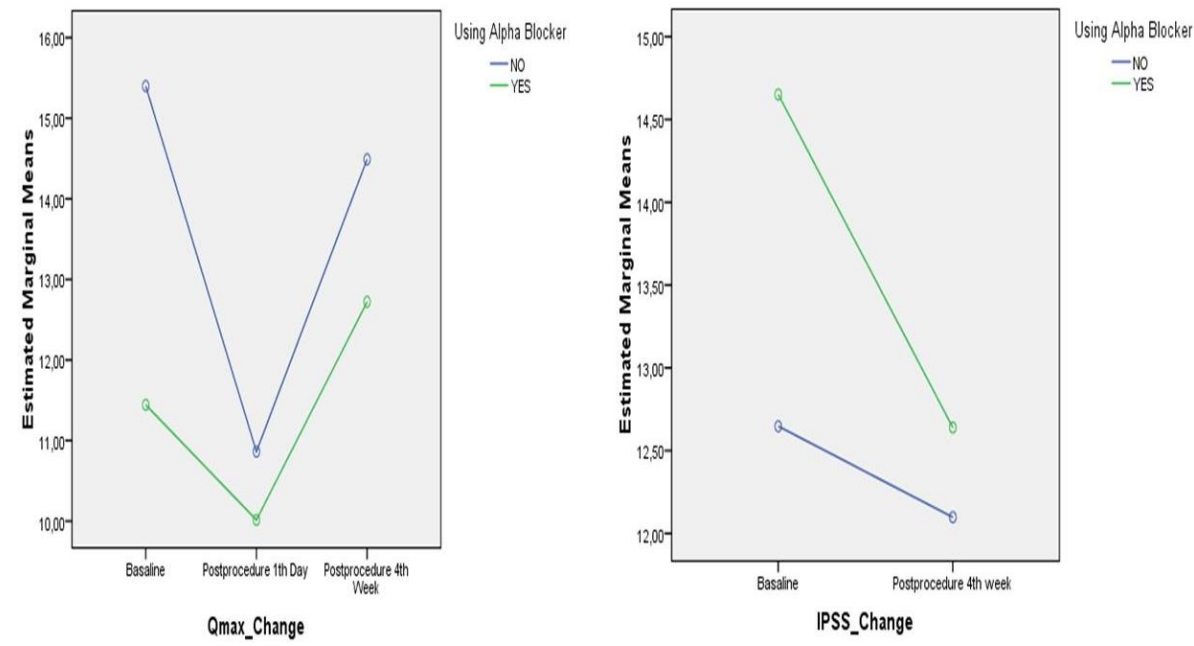

Figure 1. The change in Qmax values and I-PSS scores in repeated measures between groups.

\subsection{Uroflowmetry and Postvoid Residual Urine Volume}

In both groups, a decrease was observed in Postprocedure 1st day Qmax values compared to baseline values. During the controls performed in the 4 th week, while the decrease in group 2 reached a significantly higher value than its baseline value, it could not return to its baseline value in group 1 . The changes in Qmax values in repeated measurements were found to be statistically significant $(\mathrm{P}<0.001)$. The change in $\mathrm{Qmax}$ values was affected by the use of alpha blockers $(\mathrm{P}<0.001)$ (Figure 1). In both group, a decrease was observed in Qmax values on the postprocedure 1th day compared to baseline values. An improvement which was above postprocedure $4^{\text {th }}$ week baseline values was found in the group using alpha blockers.

With respect to the change in PVR, a decrease was observed in postprocedure 1st day PVR measurements compared to baseline values in both groups. Although PVR values were found under the baseline in the 4th week after the procedure in both groups, there were no statistically significant differences. The change in Qmax and the changes in PVR are presented in Table 4.

\subsection{Complication}

In our study, no infectious complication requiring acute urinary retention and hospitalization was observed in any patient.

\section{Discussion}

The need for prostate biopsy is based on PSA level and/or suspected DRE (Digital rectal examination) and/or imaging (Mottet et al., 2020). Short-term exacerbation of lower urinary tract symptoms (LUTS) may occur, Apart from the traditional complications of prostate biopsy, which is performed as a safe procedure (Glaser et al., 2012; Loeb et al., 2013; Namekawa et al., 2015). LUTS is evaluated by international prostate symptom score (I-PSS) as standard (Barry et al., 1992). In our study, for the evaluation of LUTS, we performed evaluations by making the measurements of maximum flow rate (Qmax) and postvoid residual (PVR) measured in addition to I-PSS evaluation.

The study carried out by Zisman et al. is one of the first publication on the effect of prostate biopsy on lower urinary tract symptoms in the literatüre (Zisman et al., 2001). In their study carried out in 2001, Zisman et al. demonstrated that prostate biopsy had a measurable effect on voiding functions (Zisman et al., 2001). In the study on the effect of multiple core prostate biopsy and periprostatic nerve block on voiding and erectile 
function, Klein et al. found an increase in I-PSS, although it was not statistically significant compared to baseline. It is a known fact that the use of alpha blocker provides improvements in LUTS symptoms and uroflowmetry parameters (Klein et al., 2010). Due to these effects, alpha blockers were encouraged to be used in patients after prostate biopsy (Schulman et al., 2001; O’Leary, 2001). In our study, in the correlation between the changes in Postprocedure first day and 4th week Qmax values compared to baseline and age, BMI, PSA, prostate volume, VAS, the use of alpha blockers, we found that both changes had a statistical effect on the use of alpha blockers.

In the literature the effects of alpha blocker use on lower urinary tract symptoms after prostate biopsy; Bozlu et al. indicated that the use of alpha blockers led to a significant increase in Qmax after biopsy (Bozlu et al., 2003). In their study, Chung et al. found that prostate biopsy led to objective voiding dysfunction and that the use of alpha blockers before biopsy increased the Qmax values after biopsy (Chung et al., 2015). In our study, we found a deterioration in Qmax and PVR parameters in patients who did not use alpha blockers and used alpha blockers on the postprocedure 1st day. In our study, a significant improvement was observed in postprocedure $4^{\text {th }}$ week Qmax values in those using alpha blockers compared to those who did not use alpha blockers. Şefik et al. found this improvement on Day 7 in patients using tamsulosin after biopsy (Şefik et al., 2020). Chung et al. reported a statistically significant increase on the $1^{\text {st }}$ day after prostate biopsy in patients who received tamsulosin, however, they did not find any difference in the control group (Chung et al., 2015). Bozlu et al. indicated that the improvement in Qmax started on the $7^{\text {th }}$ day and increased on the 30th day in patients receiving tamsulosin (Bozlu et al., 2003). In our study, we found a statistically decrease in Qmax value in both groups with and without the use of alpha blockers on the postprocedure $1^{\text {st }}$ day. We indicate that there was an even better improvement in patients using alpha blockers on the postprocedure 4th week compared to baseline values.

With respect to residual urine volume, Chung et al. did not find a significant increase in the amount of residual urine on the postprocedure $1^{\text {st }}$ day in patient group administered with tamsulosin compared to baseline, however, they found an increase in the amount of residual urine in the control group (without tamsulosin use) (Chung et al., 2015). In our study, we found that both groups had a deterioration in the residual urine volume on the first day after biopsy. Although no statistical difference was found according to the postprocedure $4^{\text {th }}$ week baseline values, less residual urine volume remains in the use of alpha blockers compared to baseline. Although none of our patients had acute urinary retention on the postprocedure $1^{\text {st }}$ day, we consider that it is necessary to watch out for the increase in residual urine volume that occurred on the first day after prostate biopsy.

With respect to the changes in I-PSS, Bozlu et al. observed a significant improvement in I-PSS on the $30^{\text {th }}$ day after biopsy in those using alpha blockers (Bozlu et al., 2003). Şefik et al. also found a similar result on the $7^{\text {th }}$ day after biopsy (SSefik et al., 2020). In our study, in consistent with the literature, we found a significant improvement in the I-PSS scores in the $4^{\text {th }}$ week after biopsy in the group using alpha blockers.

It is indicated in the literature that there is a defined correlation between BMI and LUTS (Kaplan et al., 2013). However, we did not find this correlation in the results of our study. No statistical relation was found in the BMI correlation analysis of the Qmax change. Furthermore, BMI scores for alpha blocker use were not found to be similar between the two groups. We consider that BMI has no effect on lower urinary tract symptoms due to biopsy.

In the evaluation performed for the scoring of pain perceived by the patients during biopsy, Şefik et al. (2020) found that the VAS score was $2.7 \pm 2.3$ for the group with tamsulosin use and $4.2 \pm 2.2$ for the group without tamsulosin use, and they stated that the use of tamsulosin reduced the pain. In our study, no statistical relationship was found in the VAS correlation analysis of Qmax changes. Furthermore, there was no statistically significant difference in VAS scores between the groups (for Group 1; 2.51 \pm 1.69 , for Group 2; 2.58 \pm 1.97 ). Therefore, no finding indicating that tamsulosin use reduced the perceived pain due to biopsy was found in our study.

In our study, we found that there would be a significant decrease in Qmax flow rates and an increase in residual urine volume in all patients on the $1^{\text {st }}$ day after prostate biopsy regardless of the use of alpha blockers. We believe that patients should be informed about this situation they will experience after biopsy. There will be a significant improvement in Qmax and I-PSS values in case of continued use of alpha blockers in the $4^{\text {th }}$ week after biopsy.

The current study has some limitations. In our study that was carried out in a single center, the low number of patients may have led to failure to find some parameters that may have a significant effect. In addition, the patients in the study did not use drugs such as 5 alpha reductase inhibitors. Therefore, the fact that the effects of these drugs were not evaluated is a limitation for this study. Another limitation of the study is that the patients did not have any intermediate value measurements except the $1^{\text {st }}$ day and $4^{\text {th }}$ week after the procedure.

\section{Conclusion}

Prostate biopsy is expected to cause a temporary voiding difficulty. The presence of deterioration in objective voiding symptoms 1st day after biopsy is possible despite the use of alpha blockers. It can be corrected by the continuation of the use of alpha blockers. 


\section{Author Contributions}

$\mathrm{AB}$; protocol development and research design, data collection and management, data analysis, manuscript writing/ editing, supervision. MMB; protocol development, data collection. MSÇ; protocol development, data collection. CA; protocol development, data collection. MY; protocol development, data collection. ME; protocol development, data collection. All authors read and approved the final manuscript.

\section{Conflict of Interest}

The authors declare that there is no conflict of interest.

\section{References}

Barry MJ, Fowler FJ Jr, O'Leary MP, Bruskewitz RC, Holtgrewe HL, Mebust WK, Cockett AT. 1992. The American Urological Association symptom index for benign prostatic hyperplasia. The Measurement Committee of the American Urological Association. J Urol, 148(5): 1549-1557. DOI: 10.1016/s00225347(17)36966-5.

Bozlu M, Ulusoy E, Doruk E, Cayan S, Canpolat B, Schellhammer PF, Akbay E. 2003. Voiding impairment after prostate biopsy: does tamsulosin treatment before biopsy decrease this morbidity? Urology, 62: $1050 . \quad$ DOI: 10.1016/j.urology.2003.07.006.

Chung SJ, Jung SI, Ryu JW, Hwang EC, Kwon DD, Park K, Kim JW. 2015. The preventive effect of tamsulosin on voiding dysfunction after prostate biopsy: a prospective, open-label, observational study. Int Urol Nephrol, 47: 711-715. DOI: 10.1007/s11255-015-0955-7.

Glaser AP, Novakovic K, Helfand BT. 2012. The impact of prostate biopsy on urinary symptoms, erectile function, and anxiety. Curr Urol Rep, 13: 447-454. DOI: 10.1007/s11934012-0277-6.

Hodge KK, McNeal JE, Terris MK, Stamey TA. 1989. Random systematic versus ultrasound guided transrectal core biopsies of the prostate. J Urol, 142: 71-74. DOI: 10.1016/s0022-5347(17)38664-0.

Kaplan SA, Lee JY, O'Neill EA, Meehan AG, Kusek JW. 2013. Prevalence of low testosterone and its relationship to body mass index in older men with lower urinary tract symptoms associated with benign prostatic hyperplasia. Aging Male, 16(4): 169-172. DOI: 10.3109/13685538.2013.844786.

Klein T, Palisaar RJ, Holz A, Brock M, Noldus J, Hinkel A. 2010.
The impact of prostate biopsy and periprostatic nerve block on erectile and voiding function: a prospective study. J Urol, 184: 1447-1452DOI: 10.1016/j.juro.2010.06.021.

Loeb S, Carter HB, Berndt SI, Ricker W, Schaeffer ED. 2011. Complications after prostate biopsy: data from SEERMedicare. J Urol, 186: 1830-1834. DOI: 10.1016/j.juro.2011.06.057.

Loeb S, Vellekoop A, Ahmed HU, Catto J, Emberton M, Nam R, Rosario DJ, Scattoni V, Lotan Y. 2013. Systematic review of complications of prostate biopsy. Eur Urol, 64: 876-892. DOI: 10.1016/j.eururo.2013.05.049.

Mottet N, Cornford P, van den Bergh RCN, Briers E, De Santis M, Fanti S, Gillessen S, Grummet J, Henry AM, Lam TB, Mason MD, van der KwastTH, van der Poel HG, Rouvière O, Schoots IG, Tilki D, Wiegel T. 2020. EAU Guidelines, Uroweb.org. European Association of Urology Prostate Cancer Guidelines, URL: $\quad$ http://www.uroweb.org/guideline/prostatecancer/\#5;2020 (access date: 30.07.2020) .

Namekawa T, Fukasawa S, Komaru A, Kobayashi M, Imamura Y, Ohzeki T, Takagi K, Sato Y, Akakura K, Ichikawa T, Ueda T, 2015. Prospective evaluation of the safety of transrectal ultrasound-guided transperineal prostate biopsy based on adverse events. Int J Clin Oncol, 20: 1185-1191. DOI: 10.1007/s10147-015-0831-6.

O'Leary MP. 2001. Tamsulosin: current clinical experience. Urology, 58(6 Suppl 1): 42-48; DOI: 10.1016/s00904295(01)01346-2.

Schulman CC, Lock TM, Buzelin JM, Boeminghaus F, Stephenson TP, Talja M, European Tamsulosin Study Group, 2001. Longterm use of tamsulosin to treat lower urinary tract symptoms/benign prostatic hyperplasia. J Urol, 166(4): 1358-1363.

Sefik E, Eker A, Gunlusoy B, Celik S, Bozkurt IH, Basmaci I, Polat S, Degirmenci T, Ceylan Y. 2020. The effect of alpha blocker treatment prior to prostate biopsy on voiding functions, pain scores and health-related quality-of-life outcomes: A prospective randomized trial. Prog Urol, 30(4): 198-204. DOI: 10.1016/j.purol.2019.12.006.

Stamey TA, Yang N, Hay AR, McNeal JE, Freiha FS, Redwine E. 1987. Prostate-specific antigen as a serum marker for adenocarcinoma of the prostate. N Engl J Med, 317: 909-916. DOI: $10.1056 /$ NEJM198710083171501.

Zisman A, Leibovici D, Kleinmann J, Cooper A, Siegel Y, Lindner A. 2001. The impact of prostate biopsy on patient well-being a prospective study of voiding impairment. J Urol, 166: 2242 2246. 